\title{
High-magnitude head impact exposure in youth football
}

\author{
Eamon T. Campolettano, BS, Ryan A. Gellner, BS, and Steven Rowson, PhD \\ Department of Biomedical Engineering and Mechanics, Virginia Tech, Blacksburg, Virginia
}

OBJECTIVE Even in the absence of a clinically diagnosed concussion, research suggests that neurocognitive changes may develop in football players as a result of frequent head impacts that occur during football games and practices. The objectives of this study were to determine the specific situations in which high-magnitude impacts (accelerations exceeding $40 \mathrm{~g}$ ) occur in youth football games and practices and to assess how representative practice activities are of games with regard to high-magnitude head impact exposure.

METHODS A total of 45 players (mean age $10.7 \pm 1.1$ years) on 2 youth teams (Juniors [mean age $9.9 \pm 0.6$ years; mean body mass $38.9 \pm 9.9 \mathrm{~kg}$ ] and Seniors [mean age $11.9 \pm 0.6$ years; mean body mass $51.4 \pm 11.8 \mathrm{~kg}$ ]) wore helmets instrumented with accelerometer arrays to record head impact accelerations for all practices and games. Video recordings from practices and games were used to verify all high-magnitude head impacts, identify specific impact characteristics, and determine the amount of time spent in each activity.

RESULTS A total of 7590 impacts were recorded, of which 571 resulted in high-magnitude head impact accelerations exceeding $40 \mathrm{~g}(8 \%)$. Impacts were characterized based on the position played by the team member who received the impact, the part of the field where the impact occurred, whether the impact occurred during a game or practice play, and the cause of the impact. High-magnitude impacts occurred most frequently in the open field in both games (59.4\%) and practices (67.5\%). "Back" position players experienced a greater proportion of high-magnitude head impacts than players at other positions. The 2 teams in this study structured their practice sessions similarly with respect to time spent in each drill, but impact rates differed for each drill between the teams.

CONCLUSIONS High-magnitude head impact exposure in games and practice drills was quantified and used as the basis for comparison of exposure in the 2 settings. In this cohort, game impact rates exceeded those for practice. Back players, who were often positioned in the open field, were shown to experience elevated levels of head impact exposure relative to players at other positions. The analysis also suggests that practice intensity, which may be influenced by coaching style, may also affect high-magnitude head impact exposure. Future studies should investigate this aspect as a factor affecting head impact exposure.

https://thejns.org/doi/abs/10.3171/2017.5.PEDS17185

KEY WORDS concussion; biomechanics; linear; rotational; acceleration; pediatric; trauma

$\mathrm{W}$ ITH research providing evidence suggesting that long-term neurocognitive deficits may result from repetitive sports-related concussions, these injuries have become a cause for widespread public concern..$^{21,29}$ Of all sports, football accounts for the highest incidence of concussion. ${ }^{19,20,31}$ Exposure to head impacts in football has been shown to result in neurocognitive and brain changes even in the absence of clinically diagnosed concussion. ${ }^{1,18,30}$ Most research quantifying head impact exposure in football has focused on high school, collegiate, or professional populations, despite the fact that youth football players represent $70 \%$ of all players in the United States. ${ }^{4-6,9,14,22,24-26,28}$ Proper teaching and rule modification are considered to be effective methods for limiting head impact exposure and mitigating concussions in football. ${ }^{13}$

Using helmet-mounted accelerometer arrays, previous research with youth football players has shown that most head impacts occur during practice rather than game play. ${ }^{8,10,16,33}$ The first of these studies was instrumental in the development of rule changes to limit head impact ex- 
posure in youth football players, which were instituted by the Pop Warner youth football organization. ${ }^{16}$ Following these changes, it was observed that head impact exposure was reduced by as much as $40 \%$ by limiting player-toplayer contact in practice..$^{10}$ A classification system used to assess the number and severity of high-magnitude impacts occurring in specific practice drills demonstrated that most tackling drills were associated with a greater impact severity than was game play ${ }^{8}$ and confirmed previous research indicating that the magnitude and frequency of head impacts were lower in youth players than in older players. $8,10,16,17,26,32,33$

Quantification of impact exposure for games, to this point, has been limited to either frequency or impacts per game. ${ }^{10,14,16,17,24,33}$ Although this research has been invaluable in promoting player safety, it has provided a largely superficial investigation into the circumstances surrounding game impacts, specifically those of a high magnitude. These high-acceleration impacts are associated with a greater risk of concussion than lower-acceleration impacts. ${ }^{27}$ With a valuable framework already in place to assess head impact exposure in football practices, ${ }^{8}$ the primary objective of this study was to quantify and compare high-magnitude impact exposure in games and practices. In addition, we sought to characterize impacts on the basis of the position played by the team member who received the impact, the part of the field where the impact occurred, whether the impact occurred during game or practice play, and the cause of the impact. Knowledge of the specific impact scenarios that most frequently occur in games would allow coaches and leagues to make changes that reduce player risk, such as identifying and eliminating practice drills associated with high-risk impact scenarios not observed in games. These data have applications toward improving player safety in youth football by developing interventions that limit head impact exposure.

\section{Methods \\ Study Participants}

Two youth football teams composed of 9- to 12-yearold players were included in this study, which was approved by Virginia Tech's institutional review board. All participants verbally assented to study participation, and their guardians provided written consent. A total of 45 players chose to participate and received helmets instrumented with accelerometer arrays (Head Impact Telemetry [HIT] System, Simbex). Players on the junior team (Juniors) had a mean age of $9.9 \pm 0.6$ years and a mean body mass of $38.9 \pm 9.9 \mathrm{~kg}$. Players on the senior team (Seniors) had a mean age of $11.9 \pm 0.6$ years and a mean body mass of $51.4 \pm 11.8 \mathrm{~kg}$. Overall, data were collected from 55 practice sessions and 14 games. There were 25 junior team practices and 30 senior team practices, and both teams played 7 games.

\section{Data Acquisition}

All players were provided with a Riddell Revolution or Speed helmet with a 6-accelerometer array mounted inside. To ensure measurements of head acceleration, and not helmet acceleration, the accelerometers are spring mounted to maintain contact with the head throughout the impact. ${ }^{23}$ Players wore the instrumented helmets at each practice and game throughout the season. Data acquisition for impacts was automatically triggered when an individual channel exceeded a $14.4 \mathrm{~g}$ threshold. A $10 \mathrm{~g}$ resultant acceleration threshold was used to distinguish between impact events and acceleration levels associated with nonimpact events. Impact data, which were transmitted wirelessly from the helmets to a sideline computer, were processed to compute linear and rotational resultant accelerations. ${ }^{11,28}$

Games and practices were filmed to facilitate video verification of head impacts. Any impact exceeding $40 \mathrm{~g}$ was categorized as a high-magnitude impact, which is consistent with previous studies, and represented the top $8 \%$ of all impacts recorded. All high-magnitude head impacts were visually verified to identify the scenario associated with the head impact. Activity logs recorded by researchers who were present for each session were used to parse out false impacts, which were most often associated with players dropping their helmets on the ground during breaks in action. Game video was also used to develop offensive and defensive play counts for each player.

All high-magnitude impacts were classified as occurring either in the open field or at the line of scrimmage. Open field impacts were defined as those that occurred outside the zone where the offensive linemen were positioned at the snap. Line of scrimmage impacts occurred within this zone.

Beyond this categorization, the causes of high-magnitude practice and game impacts were classified based on the role of the player who experienced the impact during the play in which the high-magnitude impact occurred. Four specific roles were identified during which players experienced head impacts: Blocked, Blocker, Tackled, and Tackler. "Blocked" refers to impacts experienced by a player who was blocked by an opposing player. "Blocker" refers to impacts experienced by a player who blocked an opposing player. "Tackled" refers to impacts experienced by a player who was tackled by an opposing player while carrying the ball. "Tackler" refers to impacts experienced by a player who tackled an opposing player who was carrying the ball. Seven isolated, high-magnitude game impacts were attributed to fumbles. In these impacts, the football was dropped by a player and nearby players dove to the ground to attempt to retrieve the ball. These impacts could not be grouped with any other impact cause and were excluded from analysis because there were too few for meaningful comparisons.

High-magnitude practice impacts were categorized according to the practice activity at the time of impact. Generalized practice activities for the teams in this study consisted of "Offense vs Defense," "Tackling-No Blocker," "Tackling-Blocker," and "Blocking." 8 Offense vs Defense represents all practice activities in which a team's offense and defense opposed each other. These took the form of intra- and intersquad 11-versus-11 scrimmages, as well as smaller-scale (5-vs-5 or 6-vs-6) scrimmages. Tackling-No Blocker consists of drills in which ball carriers and tacklers oppose each other without a blocker present. Tackling-Blocker represents a permutation of the previ- 
ous drill, with the notable difference that a blocker is present. Blocking consists of drills primarily aimed at practicing blocking or block shedding, skills that simulate work on the offensive or defensive line. These 4 generalized categories encompassed nearly all of the scenarios during which high-magnitude head impacts were observed in practice. Six high-magnitude practice impacts occurred in unique activities that could not be grouped into the previous categories and were excluded from analysis because there were too few for meaningful comparisons.

Players were assigned to 1 of 3 position groups, corresponding to their roles on the field (Table 1). Youth players generally play both offense and defense at similar positions. According to traditional football positions, offensive linemen and defensive linemen would be considered similar, and running backs and linebackers would be considered similar.

The number of high-magnitude impacts and impact rates were compared between games, practice as a whole, and specific practice drills. Using video from practices and games, the amount of time spent participating in each practice drill or game was determined. Because the amount of time spent in each activity and the number of impacts differed between the teams and between practices and games, impact rates, measured in high-magnitude impacts per hour, were used for comparisons.

\section{Statistical Analysis}

Byar's method was used to develop 95\% CIs for the impact rates in this study. This method retains accuracy when comparing large and small values, which were an aspect of this study. ${ }^{3}$ Impact rates were determined for each team for open field and line of scrimmage impacts, specific causes of impacts, and specific football activities (i.e., practice drills, overall practice, and games). Statistical significance for differences in impact rates was defined by nonoverlapping $95 \%$ CIs. For each practice drill, ANCOVA was used to determine the effects of the factors position and team on high-magnitude head impact exposure, while controlling for the continuous covariates of age, weight, and number of practices. A log transformation of high-magnitude impact counts was used to satisfy the assumption of normality, no interactions were assumed, and Type II sums of squares were computed for each factor.

\section{Results}

A total of 7590 impacts were recorded and verified, 2057 of which occurred during games (Table 2). Among all impacts, $571(8 \%)$ exceeded $40 g$ and were considered to be high magnitude. These high-magnitude impacts were composed of 381 (67\%) practice impacts and 190 (33\%) game impacts. Game impacts exceeding $40 \mathrm{~g}$ represented approximately the top $10 \%$ of all game impacts for players in this study. Among game impacts, 114 were classified as open field impacts, with the remaining 76 as line of scrimmage impacts. Among practice impacts, 263 were open field impacts and 118 were line of scrimmage impacts. In practice, Offense vs Defense drills resulted in numbers of impacts similar to those occurring in games. Practice drills varied in the breakdown of open field and
TABLE 1. Player position groups in youth football teams

\begin{tabular}{ll}
\hline Classification & \multicolumn{1}{c}{ Position } \\
\hline Back & Quarterback, running back, \& linebacker \\
\hline Line & Offensive \& defensive line \\
\hline Perimeter & Wide receiver, cornerback, \& safety \\
\hline
\end{tabular}

Players were assigned position classifications according to their roles on both offense and defense.

line of scrimmage impacts, as well as in terms of impact cause (Fig. 1).

Differences between the 2 teams were observed for high-magnitude impacts. Juniors had 65 high-magnitude head impacts (37\%) in 7 games and 113 in 25 practice sessions, whereas Seniors had 125 (32\%) in 7 games and 268 in 30 practice sessions. Juniors experienced 62 open field impacts (33\%) and 126 line of scrimmage impacts. Seniors experienced 315 open field impacts (80\%) and 78 line of scrimmage impacts.

\section{High-Magnitude Head Impact Exposure in Games}

Most high-magnitude head impacts occurred in players in the Back positions (Table 3). On average, these players had the most playing time and experienced high-magnitude impacts at a higher rate. Increased playing time was associated with an increase in high-magnitude head impacts (Line group: $\mathrm{R}^{2}=0.304, \mathrm{p}=0.0176$; Back group: $\mathrm{R}^{2}$ $=0.724, p=0.0001)$. The average Back player participated in 273 plays and experienced 9 high-magnitude head impacts, whereas the average Line player participated in 225 plays with 4 high-magnitude head impacts (Fig. 2).

Overall, a majority (59.4\%) of game impacts were observed to occur in the open field. Juniors experienced only 28 open field impacts, compared with 37 line of scrimmage impacts. Seniors experienced 86 open field impacts and 39 line of scrimmage impacts. Impact cause was associated with a player's position, in that Line players experienced a greater proportion of impacts related to blocking (Blocker or Blocked), whereas Back players experienced a greater proportion related to tackling (Tackler or Tackled). Most game impacts for Juniors (61.5\%) were associated with blocking, whereas tackling impacts (65.6\%) represented the majority for Seniors.

\section{Comparison of High-Magnitude Head Impact Exposure in Practices and Games}

Back players experienced a majority of high-magnitude impacts related to tackling $(72.3 \%)$, whereas Line players experienced most impacts due to blocking (70.9\%) (Table 4). Line players experienced most high-magnitude head impacts at the line of scrimmage (66.3\%), whereas Back players generally experienced impacts in the open field $(82.6 \%)$. This was observed to be true for both teams for both games and practices. Junior Line players tended to experience high-magnitude head impacts associated with blocking (92.5\%), while a majority of practice impacts for Senior Line players were related to tackling (55.1\%). The 2 teams in this study experienced similar numbers of impacts related to blocking. 
TABLE 2. Summary of high-magnitude head impact exposures by team

\begin{tabular}{|c|c|c|c|c|c|c|c|c|c|}
\hline \multirow[b]{2}{*}{$\begin{array}{c}\text { Team \& } \\
\text { Player No. }\end{array}$} & \multirow[b]{2}{*}{ Position } & \multirow[b]{2}{*}{$\begin{array}{l}\text { No. of } \\
\text { Games }\end{array}$} & \multirow[b]{2}{*}{$\begin{array}{l}\text { No. of } \\
\text { Plays }\end{array}$} & \multirow[b]{2}{*}{$\begin{array}{l}\text { No. of Game } \\
\text { Impacts }\end{array}$} & \multirow[b]{2}{*}{$\begin{array}{c}\text { No. of } \\
\text { Practices }\end{array}$} & \multicolumn{4}{|c|}{ Impacts by Activity Categories } \\
\hline & & & & & & Blocking & $\begin{array}{l}\text { Offense vs } \\
\text { Defense }\end{array}$ & $\begin{array}{l}\text { Tackling- } \\
\text { No Blocker }\end{array}$ & $\begin{array}{c}\text { Tackling- } \\
\text { Blocker }\end{array}$ \\
\hline \multicolumn{10}{|l|}{ Seniors } \\
\hline 1 & Line & 7 & 101 & 0 & 28 & 0 & 3 & 4 & 0 \\
\hline 2 & Perimeter & 6 & 8 & 0 & 10 & 0 & 0 & 0 & 0 \\
\hline 3 & Back & 7 & 457 & 25 & 28 & 0 & 18 & 14 & 8 \\
\hline 4 & Back & 7 & 312 & 1 & 21 & 0 & 7 & 15 & 2 \\
\hline 5 & Back & 5 & 110 & 1 & 9 & 0 & 1 & 3 & 0 \\
\hline 6 & Back & 7 & 460 & 31 & 30 & 2 & 32 & 27 & 5 \\
\hline 7 & Line & 6 & 389 & 5 & 28 & 0 & 6 & 1 & 1 \\
\hline 8 & Line & 7 & 338 & 2 & 29 & 0 & 6 & 14 & 1 \\
\hline 9 & Back & 6 & 351 & 9 & 27 & 0 & 4 & 8 & 0 \\
\hline 10 & Line & 6 & 397 & 2 & 29 & 0 & 2 & 2 & 0 \\
\hline 11 & Line & 6 & 256 & 2 & 25 & 0 & 0 & 3 & 0 \\
\hline 12 & Perimeter & 7 & 75 & 1 & 27 & 0 & 3 & 3 & 0 \\
\hline 13 & Line & 6 & 395 & 20 & 27 & 2 & 4 & 6 & 0 \\
\hline 14 & Perimeter & 3 & 25 & 0 & 14 & 0 & 2 & 5 & 0 \\
\hline 15 & Perimeter & 1 & 7 & 0 & 5 & 0 & 1 & 1 & 0 \\
\hline 16 & Line & 5 & 320 & 1 & 27 & 0 & 0 & 1 & 1 \\
\hline 17 & Back & 7 & 483 & 18 & 28 & 0 & 12 & 14 & 0 \\
\hline 18 & Back & 4 & 122 & 2 & 16 & 0 & 11 & 9 & 4 \\
\hline \multicolumn{10}{|l|}{ Juniors } \\
\hline 19 & Line & 7 & 176 & 1 & 21 & 0 & 1 & 0 & 0 \\
\hline 20 & Perimeter & 6 & 33 & 0 & 21 & 0 & 0 & 0 & 0 \\
\hline 21 & Perimeter & 5 & 187 & 0 & 22 & 0 & 3 & 0 & 0 \\
\hline 22 & Back & 6 & 351 & 11 & 24 & 0 & 3 & 2 & 0 \\
\hline 23 & Perimeter & 7 & 18 & 0 & 22 & 0 & 2 & 2 & 1 \\
\hline 24 & Line & 6 & 315 & 3 & 24 & 3 & 5 & 0 & 0 \\
\hline 25 & Back & 5 & 231 & 2 & 21 & 0 & 2 & 0 & 0 \\
\hline 26 & Line & 7 & 311 & 12 & 22 & 8 & 12 & 0 & 0 \\
\hline 27 & Line & 7 & 86 & 2 & 18 & 1 & 2 & 0 & 0 \\
\hline 28 & Line & 7 & 368 & 10 & 23 & 4 & 12 & 0 & 0 \\
\hline 29 & Perimeter & 5 & 36 & 0 & 14 & 0 & 0 & 0 & 0 \\
\hline 30 & Line & 3 & 39 & 0 & 7 & 0 & 0 & 0 & 0 \\
\hline 31 & Perimeter & 6 & 50 & 0 & 17 & 0 & 0 & 0 & 0 \\
\hline 32 & Perimeter & 6 & 108 & 0 & 22 & 1 & 2 & 0 & 0 \\
\hline 33 & Perimeter & 6 & 109 & 2 & 21 & 0 & 3 & 2 & 0 \\
\hline 34 & Line & 6 & 41 & 1 & 24 & 2 & 1 & 0 & 0 \\
\hline 35 & Back & 7 & 364 & 11 & 24 & 0 & 2 & 5 & 1 \\
\hline 36 & Line & 3 & 93 & 0 & 22 & 1 & 5 & 0 & 0 \\
\hline 37 & Perimeter & 7 & 92 & 0 & 23 & 0 & 1 & 1 & 0 \\
\hline 38 & Perimeter & 3 & 9 & 0 & 18 & 0 & 0 & 0 & 0 \\
\hline 39 & Back & 7 & 271 & 0 & 22 & 0 & 2 & 0 & 0 \\
\hline 40 & Line & 6 & 33 & 2 & 23 & 1 & 11 & 0 & 0 \\
\hline 41 & Line & 5 & 178 & 4 & 21 & 0 & 3 & 0 & 0 \\
\hline 42 & Back & 6 & 165 & 0 & 22 & 0 & 3 & 1 & 0 \\
\hline 43 & Line & 5 & 212 & 0 & 15 & 0 & 0 & 0 & 0 \\
\hline 44 & Back & 3 & 99 & 4 & 17 & 0 & 1 & 0 & 0 \\
\hline 45 & Back & 3 & 40 & 0 & 14 & 0 & 1 & 0 & 0 \\
\hline
\end{tabular}

The number of high-magnitude head impacts varied between activity, team, and position. Players who played more in general experienced a higher number of highmagnitude impacts in both practices and games. 

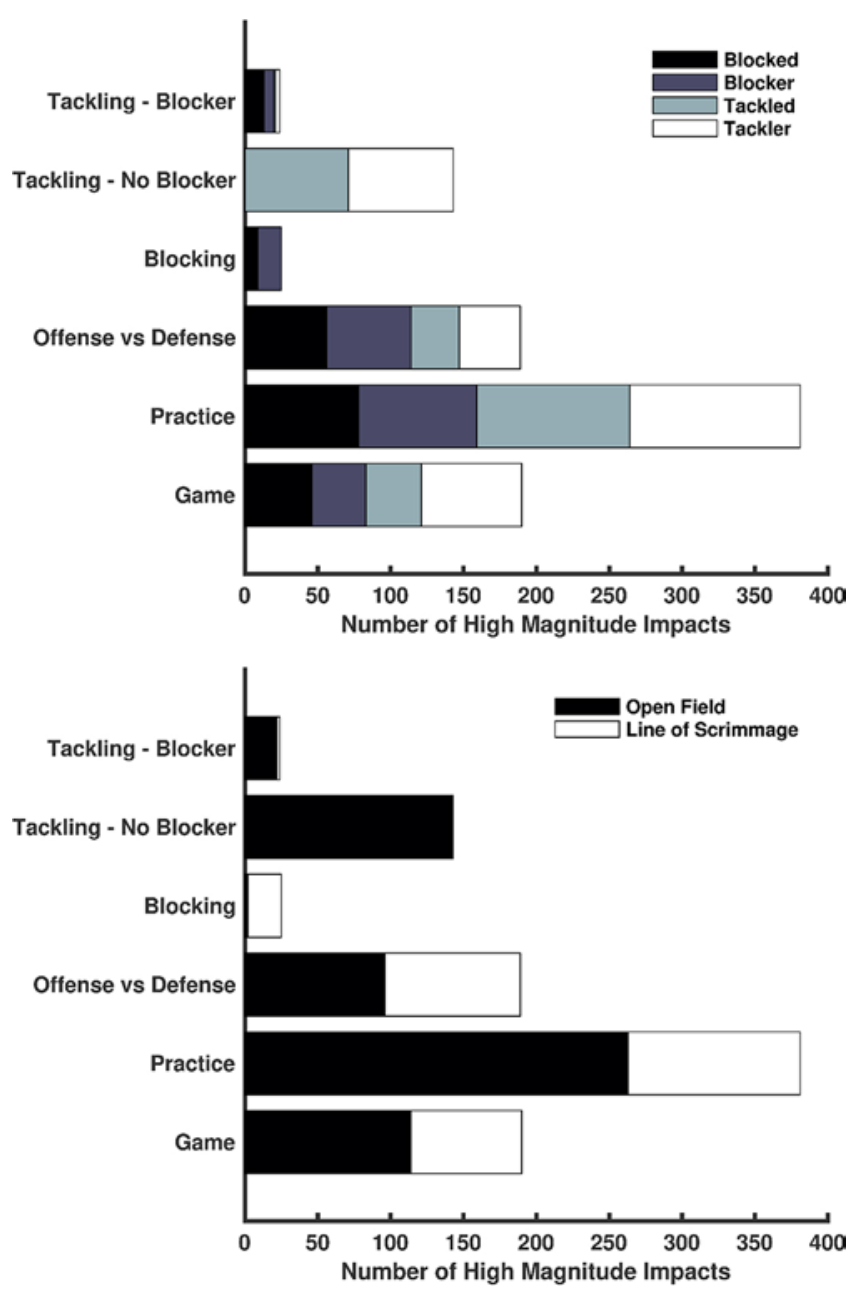

FIG. 1. Bar graphs showing high-magnitude impacts in practice drills by the cause of the impact (associated with the player's role as Blocked, Blocker, Tackling, or Tackler) (upper) and location on the field (determined by player position) (lower). Specific practice activities and games differed in the proportion of impact causes and open field impacts. Figure is available in color online only.

Both teams experienced higher impact rates in games (Juniors 95\% CI: 6.2-10.2 impacts/hour, and Seniors 95\% CI: 12.2-17.5 impacts/hour) relative to the overall practice (Juniors 95\% CI: 2.5-3.6 impacts/hour, and Seniors 95\% CI: 3.9-5.0 impacts/hour) (Fig. 3). For line of scrimmage

TABLE 3. High-magnitude head impacts based on player position

\begin{tabular}{lrrc}
\hline \multicolumn{1}{c}{ Variable } & Back & Line & Perimeter \\
\hline No. of players & 14 & 18 & 13 \\
\hline No. of impacts & 994 & 929 & 157 \\
\hline Impacts $>40 \mathrm{~g}$ & 120 & 67 & 3 \\
\hline Total no. of plays & 3816 & 4048 & 757 \\
\hline Average no. of plays & 273 & 225 & 58 \\
\hline Impacts per 100 plays & 26.0 & 22.9 & 20.7 \\
\hline Impacts $>40$ g per 100 plays & 3.1 & 1.7 & 0.4 \\
\hline
\end{tabular}

On average, backs were used most frequently and experienced the most highmagnitude head impacts.

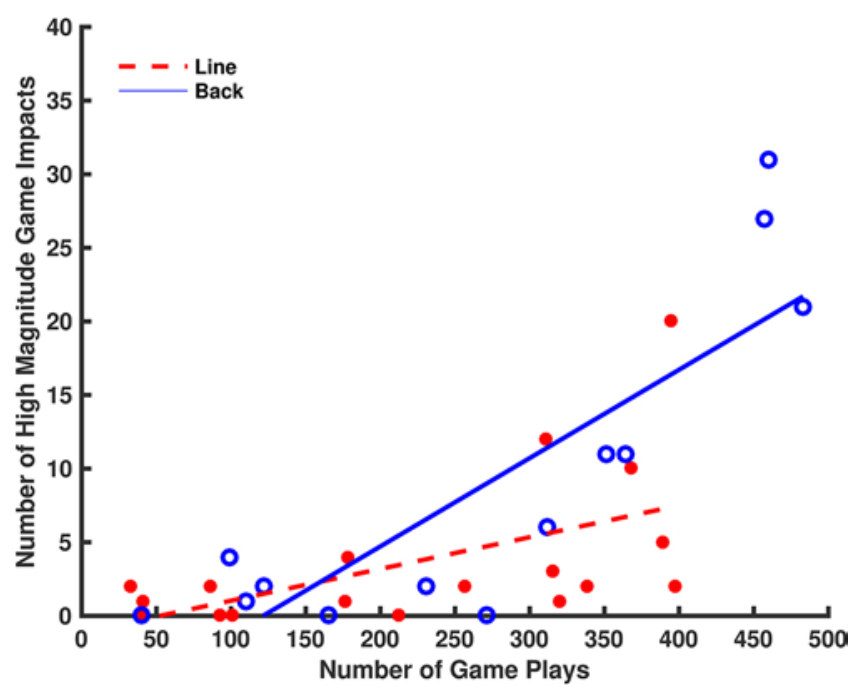

FIG. 2. Line graph showing comparison of game plays to high-magnitude impacts. Back players (open circles) participated in more plays than Line players (filled circles) and experienced more high-magnitude head impacts. Figure is available in color online only.

impacts in games, the 2 teams did not differ in impact rate (Juniors 95\% CI: 3.2-6.3 impacts/hour and Seniors 95\% CI: 3.3-6.3 impacts/hour). However, Seniors experienced a higher rate of open field game impacts $(95 \% \mathrm{CI}$ : 8.1-12.5 impacts/hour) than Juniors (95\% CI: 2.3-5.0 impacts/hour).

The percentage of all impacts that were high magnitude was determined for both teams and session types. Seniors had a higher percentage of high-magnitude impacts for both practices and games than Juniors. In practice, $4.5 \%$ of all impacts for Juniors were high magnitude, whereas $9.0 \%$ of practice impacts for Seniors exceeded $40 \mathrm{~g}$. For games, $6.6 \%$ and $11.4 \%$ of impacts for Juniors and Seniors, respectively, were categorized as high magnitude. High-magnitude impacts were $47 \%$ more likely to occur in a game than during practice for the Juniors $(95 \%$ CI: $9.8 \%-98.5 \%)$, compared with $27 \%$ for the Seniors $(95 \%$ CI: $4.0 \%-55.3 \%)$.

\section{Comparison of High-Magnitude Head Impact Exposure Between Practice Drills and Games}

The Offense versus Defense drill conducted by Juniors

TABLE 4. High-magnitude impacts by player position and location on the field

\begin{tabular}{lrrrrr}
\hline \multirow{2}{*}{$\begin{array}{c}\text { Position \& Part } \\
\text { of Field }\end{array}$} & \multicolumn{2}{c}{ Games } & & \multicolumn{2}{c}{ Practice } \\
\cline { 6 - 7 } \cline { 5 - 6 } & Tackling & Blocking & & Tackling & Blocking \\
\hline Backs & & & & & \\
\hline Open field & 90 & 6 & & 138 & 46 \\
\hline Line of scrimmage & 2 & 22 & & 15 & 20 \\
\hline Line & 13 & 2 & & 38 & 13 \\
\hline Open field & 0 & 52 & & 6 & 72 \\
\hline Line of scrimmage & 0 & & & \\
\hline
\end{tabular}

Most impacts were observed to occur in the open field. 


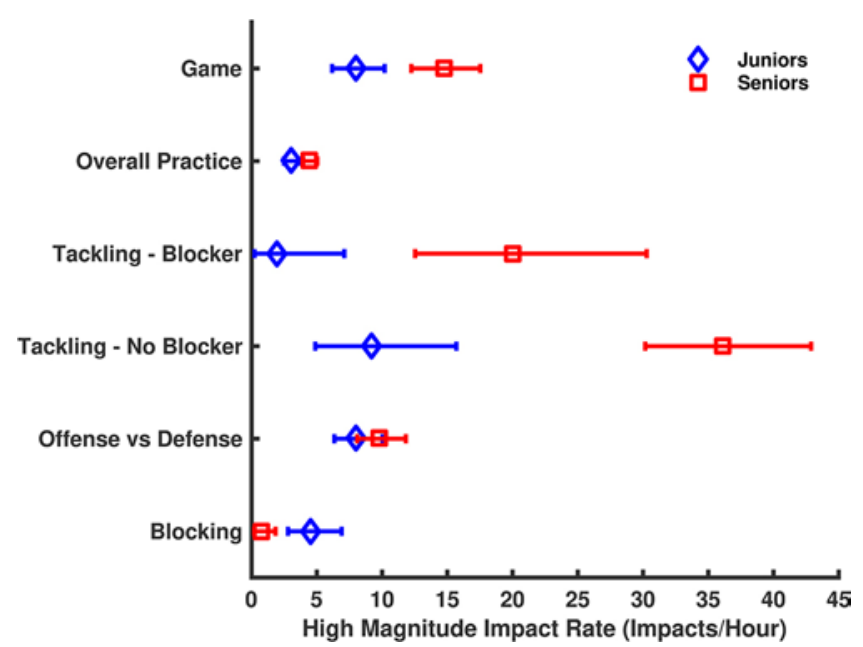

FIG. 3. Box plot showing impact rates for all football activities by team. For both teams, games were associated with a high-magnitude impact rate greater than that in practices overall. Tackling-No Blocker had the greatest high-magnitude impact rate among all practice drills. Impact rates for Seniors exceeded impact rates for Juniors for most activities. Figure is available in color online only.

resulted in an impact rate (95\% CI: 6.3-10.0 impacts/hour) that was consistent with that observed in games $(95 \% \mathrm{CI}$ : 6.2-10.2 impacts/hour). Seniors (95\% CI: 12.2-17.5 impacts/hour) experienced nearly double the impact rate in games that Juniors (95\% CI: 6.2-10.2 impacts/hour) experienced. The Tackling-No Blocker drill (95\% CI: 30.2$42.9 \mathrm{impacts} /$ hour) was associated with the highest impact rate of all football activities for Seniors (Fig. 3). For the Tackling-No Blocker drill, position $(\mathrm{p}=0.004)$ and team ( $p<0.0001)$ had an effect on high-magnitude impact exposure. Position explained $15.9 \%$ of the variance, whereas team explained $23.1 \%$. For the Tackling-Blocker drill, neither position nor team had an effect on high-magnitude impact exposure. Position was observed to have an effect for both Offense vs Defense $(\mathrm{p}=0.030)$ and Blocking drills $(p=0.012)$, explaining $12.0 \%$ and $19.5 \%$ of variance, respectively. For all drills, differences between individual players explained the majority of variance. No difference between impact rates for tackling drills and games was observed for Juniors, whereas the impact rates for tackling drills for Seniors were as high as or higher than in games.

\section{Discussion}

Given that in other studies youth football practices have been observed to be associated with a higher frequency of high-magnitude head impacts than games, head impact exposure research at the youth level has focused on efforts to limit practice impacts. High-magnitude head impacts are associated with the greatest risk for concussion. ${ }^{27}$ Knowledge of the specific impact scenarios that most frequently occur in games would allow coaches and leagues to construct practice drills that more effectively mimic these impacts rather than exposing players to more severe impacts than they might experience in a game. ${ }^{8}$ Although the proportion of high-magnitude practice impacts in our study (66\%) is low compared with those reported for pre- vious studies of youth players, it should be noted that this has been shown to be dependent on specific characteristics of individual teams, and that the average age of players in this study is older than that for youth teams in previous studies. ${ }^{8,10,16}$ As players age, more high-magnitude impacts occur during games than in practices. ${ }^{10}$

\section{High-Magnitude Head Impact Exposure in Games}

The 2 teams in this study experienced a similar number of high-magnitude line of scrimmage impacts ( 37 for Juniors and 39 for Seniors), but the proportion of game impacts at the line of scrimmage differed (56.9\% for Juniors vs $31.2 \%$ for Seniors). For both teams, Back players experienced the majority of high-magnitude game impacts in the open field and Line players experienced a majority at the line of scrimmage. Players involved in open field impacts are able to reach greater speeds and produce higher-magnitude head impacts more frequently. Among the players in various positions, Back players (41.5 $\pm 6.6 \mathrm{~kg})$, who participated in the highest number of plays on average, were the most active and athletic players, whereas Line players $(52.8 \pm 12.4 \mathrm{~kg})$ tended to be larger. Players were generally exposed to high-magnitude impacts in a manner that was consistent with where they lined up prior to the beginning of the play, which reflects the influence of player position on the incidence of high-magnitude impacts (Fig. 2).

Each position group was associated with a distinct distribution of impact causes. Line players predominately experienced impacts related to blocking, whereas Back players experienced more tackling-related impacts. Youth football offenses tend to be run oriented, which means that usually only a few offensive players (Backs) possess the ball during plays. These players represent the main target for opposing players and are therefore more likely to experience high-magnitude impacts than are their teammates at other positions. Juniors experienced a majority of their high-magnitude game impacts due to blocking. When players are younger, they are more likely to bunch up. It is often more difficult for these players to generate much speed prior to impact, so tackling-related impacts for players on the Juniors team would generally be lower in magnitude. The similar number of blocking impacts between the 2 teams would suggest that age or style of play does not affect the incidence of high-magnitude impacts near the line of scrimmage. The fact that Seniors experienced a much greater number and proportion of open field impacts than Juniors provides further evidence that player speed and age are factors associated with the rate and magnitude of head impact exposure.

\section{Comparison of High-Magnitude Head Impact Exposure in Practices and Games}

Regardless of whether players were participating in practices or games, Juniors experienced fewer high-magnitude head impacts than Seniors. This finding could be related to any number of factors, including age and practice structure, as well as practice intensity. For both teams, practice was associated with a lower likelihood of highmagnitude head impact exposure than games. For Juniors, 1 in 15 game impacts was high magnitude, whereas for Se- 
niors 1 in 9 impacts was high magnitude. Larger and faster players can deliver an impact with greater energy than smaller players, which would explain some of the observed differences in high-magnitude head impact exposure between the 2 teams. Compared with Junior practices, Senior practices were twice as likely to produce high-magnitude impacts; this difference may be attributable to increased intensity of the Senior practices-although difficult to quantify, we observed that the intensity of practices for Seniors was noticeably higher than that for Juniors. Practice structure and coaching style could expose players to more situations that result in high-magnitude impacts or that reward players for making bigger hits, rather than safer hits, in player-to-player contact.

For both teams, the high-magnitude impact rate was increased in games compared with practices (Fig. 3). Practices had more noncontact time than games did, which probably contributed to some of the differences observed. The differences in game style between the age groups were manifested in a higher open field impact rate for Seniors (95\% CI: 8.1-12.5 impacts/hour) relative to Juniors (95\% CI: 2.3-5.0 impacts/hour). The older players had more experience playing football and were more likely to make plays in the open field. In games and practice, most impacts for Backs were observed to be in the open field and to be related to tackling, whereas Line players experienced a majority of line of scrimmage impacts related to blocking. Players were exposed to impact scenarios in practice that were representative of game situations they would experience.

\section{Comparison of High-Magnitude Head Impact Exposure Between Practice Drills and Games}

Practice sessions lasted 90 minutes for Juniors and 120 minutes for Seniors. On average, 40 minutes were devoted to warming up or cooling down before and after practice for both teams. Both teams conducted Blocking (11 minutes) and Offense versus Defense (23 minutes) drills for the same amount of time in an average practice. Juniors did tackling drills, with or without a blocker, for 5 minutes in an average practice, compared with 9 minutes for Seniors (Table 5). The remaining time, 10 minutes for Juniors and 37 minutes for Seniors, was devoted to water breaks, coaching instruction, and position-specific, noncontact drills. Not every drill was done at each practice, and the average practice time represents an aggregation over the course of the season.

On average, practice drills that produced high-magnitude head impacts were conducted for similar amounts of time between the 2 teams. The only difference was that Seniors conducted 4 more minutes of tackling drills than Juniors. It has been estimated that a 5-minute reduction in tackling drills could decrease the incidence of high-magnitude impacts by as much as $19 \% .{ }^{8}$ This slight difference in practice structure would not explain all of the difference in high-magnitude practice impacts between the 2 teams in this study (113 for Juniors and 268 for Seniors). The older, larger players on the Senior team would be expected to experience high-magnitude head impacts more frequently than their Junior counterparts. Because the covariates of age, weight, and number of practices were the first to be
TABLE 5. Time spent in practice drills by 2 youth football teams

\begin{tabular}{lcc}
\hline \multicolumn{1}{c}{ Activity } & Juniors (mins) & Seniors (mins) \\
\hline Tackling-No Blocker & 3 & 7 \\
\hline Tackling-Blocker & 2 & 2 \\
\hline Blocking & 11 & 11 \\
\hline Offense vs Defense & 23 & 23 \\
\hline Warm-up or cool-down & 40 & 40 \\
\hline All other activities & 10 & 37 \\
\hline
\end{tabular}

Drills that produced high-magnitude impacts in practice were conducted for a similar amount of time by both teams in this study. The Seniors team conducted 4 additional minutes of tackling drills.

controlled for when determining the effect of the position and team factors, one interpretation is that this team effect represents a correlate for practice intensity. The effect of team was shown to be significantly different between the 2 teams for the Tackling-No Blocker drill. The data suggest that a team that practices in a manner that produces high-magnitude impacts more frequently is more likely to experience high-magnitude impacts in games. The practice structure did not differ between these teams, but the intensity of some drills did. When accounting for differences in practice length, Seniors still hit more frequently than did Juniors. For Seniors, the practice impact rate (95\% CI: 3.9-5.0 impacts/hour) exceeded that of Juniors (95\% CI: 2.5-3.6 impacts/hour). For both teams, games were associated with an impact rate nearly 3 times that observed in practice. Although Senior practice was more intense and produced high-magnitude impacts more frequently than Junior practice, the level of intensity between practice and game increased markedly.

\section{Limitations of the Study}

This study had several limitations. For individual measurements, the HIT system is associated with random error up to $15.7 \%$, although the average error is only $1 \%{ }^{2}$ Distributions of data were used for analysis throughout this manuscript in an effort to minimize the effects of any measurement error. Head impact exposure varied among individuals and between the teams in this study, and would probably vary were similar analyses to be conducted with other individuals and teams. ${ }^{5-8,10,12-17,32,33}$ The number of players on both teams in this study probably contributed to the play counts determined, and would vary by age group and team size. Practice structure and the game-to-practice ratio will also probably vary by age group and by league. Assessment of coaching style and practice intensity was explored across 2 unmatched age groups, rather than with matched age groups. By accounting for age-related factors in the linear model before considering the effect of practice intensity on head impact exposure, errors in inference were minimized. Last, this analysis was restricted to highmagnitude impacts, which are those that are most likely to be visually verified. Analysis considering lower-magnitude impacts as well might provide different results, at the expense of certainty regarding the data set and conclusions resulting from the analysis. 


\section{Conclusions}

Head impact kinematic data were collected from 2 youth football teams composed of players 9-12 years old, who were assigned to a Junior or Senior team on the basis of age. The data were collected to determine where on the field high-magnitude head impacts occur, how head impact exposure varies according to the player position in games, and how representative practice is of games in regard to head impact rate and magnitude. Most high-magnitude impacts (exceeding 40g) were found to occur in the open field. Back players were usually involved in these openfield impacts, whereas Line players experienced the majority of impacts at the line of scrimmage. We developed a framework for assessing practice impact rates relative to games, which can be considered a baseline. Although the impact rate was lower in practice than in games for both teams, practices occur more frequently than games and expose players to a higher number of high-magnitude head impacts. The 2 teams in this study structured their practices similarly, but the Senior team experienced more than double the number of high-magnitude practice impacts. Differences in age and weight between teams did not account for all differences in high-magnitude head impact exposure. The data suggest that coaching style or practice intensity may also be an important factor in high-magnitude head impact exposure. How practice activities are conducted contributes toward the overall high-magnitude head impact exposure for practice, not just the practice activity itself. This analysis, augmented by the previously developed practice framework, ${ }^{8}$ may be of use to researchers or policy makers seeking to reduce head impact exposure in youth football.

\section{Acknowledgments}

Research reported in this publication was supported by the National Institute of Neurological Disorders and Stroke of the NIH under Award Number R01NS094410. The content is solely the responsibility of the authors and does not necessarily represent the official views of the NIH. We gratefully acknowledge the Blacksburg youth football teams for their participation in this study.

\section{References}

1. Bahrami N, Sharma D, Rosenthal S, Davenport EM, Urban JE, Wagner B, et al: Subconcussive head impact exposure and white matter tract changes over a single season of youth football. Radiology 281:919-926, 2016

2. Beckwith JG, Greenwald RM, Chu JJ: Measuring head kinematics in football: correlation between the head impact telemetry system and Hybrid III headform. Ann Biomed Eng 40:237-248, 2012

3. Breslow NE, Day NE: Statistical Methods in Cancer Research. Lyon, France: International Agency for Research on Cancer, 1987, Vol 2

4. Broglio SP, Schnebel B, Sosnoff JJ, Shin S, Fend X, He X, et al: Biomechanical properties of concussions in high school football. Med Sci Sports Exerc 42:2064-2071, 2010

5. Broglio SP, Sosnoff JJ, Shin S, He X, Alcaraz C, Zimmerman J: Head impacts during high school football: a biomechanical assessment. J Athl Train 44:342-349, 2009

6. Broglio SP, Surma T, Ashton-Miller JA: High school and collegiate football athlete concussions: a biomechanical review. Ann Biomed Eng 40:37-46, 2012
7. Brolinson PG, Manoogian S, McNeely D, Goforth M, Greenwald R, Duma S: Analysis of linear head accelerations from collegiate football impacts. Curr Sports Med Rep 5:23-28, 2006

8. Campolettano ET, Rowson S, Duma SM: Drill-specific head impact exposure in youth football practice. J Neurosurg Pediatr 18:536-541, 2016

9. Centers for Disease Control and Prevention: Nonfatal traumatic brain injuries related to sports and recreation activities among persons aged $\leq 19$ years-United States, 2001-2009. MMWR Morb Mortal Wkly Rep 60:1337-1342, 2011

10. Cobb BR, Urban JE, Davenport EM, Rowson S, Duma SM, Maldjian JA, et al: Head impact exposure in youth football: elementary school ages 9-12 years and the effect of practice structure. Ann Biomed Eng 41:2463-2473, 2013

11. Crisco JJ, Chu JJ, Greenwald RM: An algorithm for estimating acceleration magnitude and impact location using multiple nonorthogonal single-axis accelerometers. J Biomech Eng 126:849-854, 2004

12. Crisco JJ, Fiore R, Beckwith JG, Chu JJ, Brolinson PG, Duma $\mathrm{S}$, et al: Frequency and location of head impact exposures in individual collegiate football players. J Athl Train 45:549-559, 2010

13. Crisco JJ, Greenwald RM: Let's get the head further out of the game: a proposal for reducing brain injuries in helmeted contact sports. Curr Sports Med Rep 10:7-9, 2011

14. Crisco JJ, Wilcox BJ, Beckwith JG, Chu JJ, Duhaime AC, Rowson S, et al: Head impact exposure in collegiate football players. J Biomech 44:2673-2678, 2011

15. Crisco JJ, Wilcox BJ, Machan JT, McAllister TW, Duhaime AC, Duma SM, et al: Magnitude of head impact exposures in individual collegiate football players. J Appl Biomech 28:174-183, 2012

16. Daniel RW, Rowson S, Duma SM: Head impact exposure in youth football. Ann Biomed Eng 40:976-981, 2012

17. Daniel RW, Rowson S, Duma SM: Head impact exposure in youth football: middle school ages 12-14 years. J Biomech Eng 136:094501, 2014

18. Davenport EM, Whitlow CT, Urban JE, Espeland MA, Jung Y, Rosenbaum DA, et al: Abnormal white matter integrity related to head impact exposure in a season of high school varsity football. J Neurotrauma 31:1617-1624, 2014

19. Dick R, Ferrara MS, Agel J, Courson R, Marshall SW, Hanley MJ, et al: Descriptive epidemiology of collegiate men's football injuries: National Collegiate Athletic Association Injury Surveillance System, 1988-1989 through 2003-2004. J Athl Train 42:221-233, 2007

20. Gessel LM, Fields SK, Collins CL, Dick RW, Comstock RD: Concussions among United States high school and collegiate athletes. J Athl Train 42:495-503, 2007

21. Gottschalk AW, Andrish JT: Epidemiology of sports injury in pediatric athletes. Sports Med Arthrosc Rev 19:2-6, 2011

22. Langlois JA, Rutland-Brown W, Wald MM: The epidemiology and impact of traumatic brain injury: a brief overview. $\mathbf{J}$ Head Trauma Rehabil 21:375-378, 2006

23. Manoogian S, McNeely D, Duma S, Brolinson G, Greenwald $\mathrm{R}$ : Head acceleration is less than 10 percent of helmet acceleration in football impacts. Biomed Sci Instrum 42:383388, 2006

24. Mihalik JP, Bell DR, Marshall SW, Guskiewicz KM: Measurement of head impacts in collegiate football players: an investigation of positional and event-type differences. Neurosurgery 61:1229-1235, 2007

25. Pellman EJ, Viano DC, Tucker AM, Casson IR, Waeckerle JF: Concussion in professional football: reconstruction of game impacts and injuries. Neurosurgery 53:799-814, 2003

26. Rowson S, Brolinson G, Goforth M, Dietter D, Duma S: Linear and angular head acceleration measurements in collegiate football. J Biomech Eng 131:061016, 2009 
27. Rowson S, Duma SM: Brain injury prediction: assessing the combined probability of concussion using linear and rotational head acceleration. Ann Biomed Eng 41:873-882, 2013

28. Rowson S, Duma SM, Beckwith JG, Chu JJ, Greenwald RM, Crisco JJ, et al: Rotational head kinematics in football impacts: an injury risk function for concussion. Ann Biomed Eng 40:1-13, 2012

29. Stern RA, Riley DO, Daneshvar DH, Nowinski CJ, Cantu $\mathrm{RC}, \mathrm{McKee}$ AC: Long-term consequences of repetitive brain trauma: chronic traumatic encephalopathy. PM R 3 (10 Suppl 2):S460-S467, 2011

30. Talavage TM, Nauman EA, Breedlove EL, Yoruk U, Dye AE, Morigaki KE, et al: Functionally-detected cognitive impairment in high school football players without clinicallydiagnosed concussion. J Neurotrauma 31:327-338, 2014

31. Thurman DJ, Branche CM, Sniezek JE: The epidemiology of sports-related traumatic brain injuries in the United States: recent developments. J Head Trauma Rehabil 13:1-8, 1998

32. Urban JE, Davenport EM, Golman AJ, Maldjian JA, Whitlow CT, Powers AK, et al: Head impact exposure in youth football: high school ages 14 to 18 years and cumulative impact analysis. Ann Biomed Eng 41:2474-2487, 2013

33. Young TJ, Daniel RW, Rowson S, Duma SM: Head impact exposure in youth football: elementary school ages 7-8 years and the effect of returning players. Clin J Sport Med 24:416-421, 2014

\section{Disclosures}

The authors report no conflict of interest concerning the materials or methods used in this study or the findings specified in this paper.

\section{Author Contributions}

Conception and design: Rowson. Acquisition of data: Campolettano, Gellner. Analysis and interpretation of data: Campolettano. Drafting the article: Campolettano. Critically revising the article: Rowson, Campolettano. Reviewed submitted version of manuscript: all authors. Statistical analysis: Rowson, Campolettano. Study supervision: Rowson.

\section{Correspondence}

Steven Rowson, Biomedical Engineering and Mechanics, Virginia Tech, 343 Kelly Hall, 325 Stanger St., Blacksburg, VA 24061. email: rowson@vt.edu. 